\title{
The Influence of French on Learning English Vocabulary for L1 Arabic Speakers
}

\author{
Fatiha Sadouki \\ University of Szeged, Hungary
}

\begin{abstract}
:
The present study is an attempt to explore the cross-linguistic influence of French on the learning of English vocabulary for L1 Arabic Speakers who have French as L2 and English as L3 in Algeria. In order to investigate this issue, 30 first-year students, at Metkanat Hasi El-ghara Al-gharbiya secondary school - Lmniaa in Algeria, were asked to fill in the gap exercises. They were designed in order to find out how French knowledge affects English and what types of lexical transfer students encountered to be analyzed qualitatively. The findings showed that students tend to transfer from French which support the idea that transfer occurs due to the similarities that exist between languages.
\end{abstract}

Keywords: Arabic; English; French; Language transfer; the acquisition of vocabulary. 